\title{
NOVOS MODELOS ORGANIZACIONAIS E REPERCUSSÕES NA GESTÃO DOS RECURSOS HUMANOS: estudo de caso em Salvador-Ba.
}

FERNANDES, Sônia. R. P'; LEAL, Guacyra ${ }^{2}$; MATOS, Renata ${ }^{3}$

\section{RESUMO}

As transformações no mundo do trabalho têm impulsionado novos modelos organizacionais, refletindo nas práticas gerenciais e na gestão de recursos humanos (DRUCK, 1999; MENDES, 1997; VELOSO 1999). Este estudo objetivou analisar uma organização do segmento de serviços e suas estratégias gestão dos recursos humanos. A investigação adotou o desenho de corte transversal e foi estruturada em dois momentos. Os resultados indicam que o modelo organizacional é tipico da reorganização produtiva - estrutura central com poucos trabalhadores e terceirização dos serviços. Também, a organização assemelha-se ao modelo simples (Robbins) e apresenta características predominantes da metáfora da máquina (Morgan). Finalmente, as estratégias de gestão de recursos humanos, especialmente a partir do estilo de liderança adotado, tëm refletido no clima organizacional que foi avaliado pelos trabalhadores como positivo. Entretanto, as estratégias de desenvolvimento de recursos humanos - avaliação de desempenho e remuneração - não correspondem ao preconizado nas atuais concepções sobre gestão de pessoas.

PALAVRAS-CHAVE: desenvolvimento recursos humanos; gestão recursos humanos; modelos organizacionais

\section{ABSTRACT}

The transformations in the workplace have propelled new organizational models, reflecting on managerial practices and resource management (DRUCK, 1999; MENDES, 1997; VELOSO, 1999). This study was aimed analyze an organization belonging to the service sector and the strategies used by such organization in the management of human resources. The investigation followed a cross seccional design and it was structured in two distinct moments. The results indicate that the organizational model is typical of the productive reorganization - a central structure with few workers and contractors. In addition, the organization resembles the simple model (Robbins) and presents some characteristics of the machine metaphor (Morgan). Lastly,

\footnotetext{
${ }^{1}$ Docente do Curso de Psicologia da Unifacs; Doutora em Saúde Pública Av. Paulo VI; 2240; apt ${ }^{\circ}$ 604; Itaigara; Salvador-Ba; CEP: 41810-001 e-mail: soniareg@edpn.com.br

${ }^{2}$ Aluna do Curso de Psicologia - Unifacs

${ }^{3}$ Aluna do Curso de Psicologia - Unifacs
} 
Revista Eletrônica de Ciência Administrativa (RECADM) - ISSN 1677-7387

Faculdade Cenecista de Campo Largo - Coordenação do Curso de Administração

v. 2, n. 1, maio/2003 - http://revistas.facecla.com.br/index.php/recadm/

the strategies for human resources management, taking into consideration the adopted leadership style, have had an impact on the organizational atmosphere, which was evaluated by the employees as being positive. Nevertheless, the strategies for human resources development - evaluation of performance and salary - do not correspond to the preconceived standard based on current conceptions about human management.

KEYWORDS: human resources development; human resources management; organizational models.

\section{INTRODUÇÃO}

Após as décadas de 60 e 70, os modelos fordistas e tayloristas atravessaram uma grande crise com o crescimento da concorrência internacional. A separação entre concepção e execução, base destes modelos remonta a separação entre capital e trabalho, anterior ao taylorismo. É interessante que estes modelos conseguiram por meio de estratégias gerenciais, configurar no plano da subjetividade e da cultura o mesmo papel desempenhado pelas máquinas (eficiência, controle, certeza) confirmando a submissão do trabalho ao capital. A partir da implantação destas formas de gerenciamento o trabalhador passou a ser considerado como uma parte do processo de trabalho, diminuindo a sua autonomia nos contextos de trabalho. Por outro lado, os efeitos desta crise acabaram anunciando algumas mudanças que hoje estão em pleno curso e apresentam reflexos no mundo do trabalho, como: polivalência dos trabalhadores; mudanças nas políticas de gestão e organização do trabalho; mudanças nos mercados de produtos que exigem qualidade e diferenciação (Druck, 1999; Mendes, 1997). Adicionalmente, o preconizado toyotismo parece ter sido implantado, apenas nas grandes empresas, já que nas pequenas, 0 que mais ocorre é a subcontratação, a baixa qualificação, a reduzida participação dos trabalhadores nas decisões e a pouca atenção à gestão de qualidade. Estes aspectos são resíduos, ou melhor, estratégias da nova reestruturação produtiva, visando proteger o denominado trabalho limpo nas grandes e modernas empresas, que primam pela qualificação profissional e flexibilidade na gestão.

Um fator que merece atenção é a pequena participação dos trabalhadores nas práticas e políticas de gestão, mesmo nas empresas ditas mais inovadoras. No país, ainda há uma excessiva preocupação com o controle do trabalho que "se reflete na adoção de formas rígidas de alocação de tarefas, desenho de postos de trabalho e hierarquização do conhecimento sobre o trabalho" (Carvalho, 1994:140), e que acaba limitando os processos de aprendizagem e inovação global. 
Revista Eletrônica de Ciência Administrativa (RECADM) - ISSN 1677-7387

Faculdade Cenecista de Campo Largo - Coordenação do Curso de Administração

v. 2, n. 1, maio/2003 - http://revistas.facecla.com.br/index.php/recadm/

No contexto atual do mundo do trabalho, pode-se observar que aliada à redução de jornada de trabalho, ocorre a contratação de trabalhadores por hora, intensificação do trabalho e o uso de horas extras. Além destes aspectos, observa-se a elevada rotatividade dos trabalhadores nos postos de trabalho.

A outra tendência crescente de flexibilização dos postos de trabalho, no Brasil, tem tido reflexos negativos na terceirização e na configuração dos subempregos. Assim, o discurso organizacional dominante incorpora elementos das experiências suecas e japonesas como: a exigência de qualidade de serviços e mudanças nas práticas gerenciais cuja eficiência deve estar ligada à "integração entre 'como fazer' e os resultados, bem como a descentralização das decisões, autonomia, flexibilidade hierárquica, criatividade, incentivo à participação, valorização e qualificação dos trabalhadores" (Mendes, 1997:.58). A tradicional divisão do trabalho é modificada, pois os dois planos de concepção-programação e de execução podem estar juntos num mesmo plano de trabalho. Neste sentido, este trabalho além de gerar sobrecarga, especialmente, de natureza cognitiva, poderá levar o trabalhador a ficar cada vez mais isolado do grupo de trabalho. Adicionalmente, ocasiona um incremento nas atividades de esforço físico, estático, visuais e mentais, além de exigir mais responsabilidade e qualificação. "Se as novas tecnologias podem em menor ou maior grau, modificar o conteúdo organizacional do trabalho em uma empresa, permitindo a redução da jornada de trabalho, em muitos casos, o número de turnos e horas para desenvolver a tarefa, entretanto o trabalho se torna mais intenso e compacto, com incremento da fadiga". (Moura, 1993:69)

Os novos cenários no mundo do trabalho oriundos das transformações decorrentes das mudanças tecnológicas, estruturais e econômicas são analisadas por Veloso et alii (1999), assinalando que esta realidade tem repercutido nos modelos organizacionais e, também, nos trabalhadores na perspectiva da organização do trabalho, das relações de trabalho e da saúde. Ao analisarem esta nova realidade do mundo do trabalho e seus reflexos, Veloso et alii (1999:59) assinalam:

“ $A$ gestão de recursos humanos, portanto, ganha uma conotação estratégica, ao mesmo tempo em que se complexifica. Ela passa a servir como forma de canalização da produção e da força de trabalho para a construção de uma empresa voltada para ainovação, flexibilidade, criatividade mudança e renovação, garantindo a competitividade no contexto instável. Ao mesmo tempo, vê-se na difícil tarefa de ter que lidar com aspectos tais como trabalho em 
Revista Eletrônica de Ciência Administrativa (RECADM) - ISSN 1677-7387

Faculdade Cenecista de Campo Largo - Coordenação do Curso de Administração

v. 2, n. 1, maio/2003 - http://revistas.facecla.com.br/index.php/recadm/

equipe, subjetividade do trabalhador, cultura organizacional, dentre tantos outros, visando a consecução dos objetivos empresariais".

O trabalho nas organizações contemporâneas vem sofrendo grandes transformações devido ao processo de reestruturação produtiva que vem ocorrendo desde os anos 90 (Araújo e Moreira, 2001). Essas mudanças têm reflexos diretos no âmbito organizacional, entre outros, na perspectiva da cultura e das estratégias de gestão de recursos humanos. Assim, segundo os autores o ambiente organizacional diante destas transformações vive instabilidades internas, tanto no trabalho em si como no clima organizacional. Além de ser afetado por mudanças na tecnologia, estrutura, cultura e política de gestão para atender as novas necessidades do mercado. Este fato revela uma tendência a maior flexibilidade da organização, e inevitavelmente, nos trabalhadores em virtude da terceirização, da concentração do capital, da competitividade, da racionalidade e da qualidade de serviços (Dellagnello e Silva, 2000).

Interessante é que Leite (1995 apud por Veloso et alii 1999), salienta que a expansão das técnicas gerenciais japonesas nos países em desenvolvimento tem levado a uma difusão da precarização do trabalho, diferenciando cada vez mais os trabalhadores que são centrais e periféricos.

Para compreender melhor estas mudanças e as tendências do ambiente organizacional é necessário focalizar também as estruturas organizacionais que caracterizam o contexto do trabalho. Dentro desta perspectiva, Morgan (1996) faz uma análise das organizações utilizando metáforas, ente as quais, a da máquina, do cérebro e da cultura. Vale ressaltar, que as organizações, normalmente, apresentam características inerentes a mais de uma destas metáforas, havendo o predomínio de uma delas. Segundo Morgan (1996), a organização pode ser vista como máquina quando a realização do seu trabalho ocorre de maneira mecanicista, rotinizada, padronizada e sem exigir muito esforço mental. Estas organizações são, também, chamadas de burocráticas e suas atividades são extremamente fragmentadas, coordenadas e controladas o que produz um pensamento mecânico. Esta perspectiva mecanicista tende a limitar o desenvolvimento do indivíduo de maneira a modelar o trabalhador para que este atenda as exigências e metas da organização.

Outra metáfora apresentada por Morgan (1996), considera a organização como um cérebro. Assim, este autor, apresenta a possibilidade da organização "desenvolver a habilidade para realizar o processo de organização de maneira que promova a ação flexível e criativa"(MORGAN, 1996, p.82). Essa metáfora aponta para a capacidade deste tipo de organização estar questionando as transformações situacionais e adaptando-se rápida e eficazmente as mudanças do ambiente. Com isso, a organização revela uma ação "substancialmente" racional (Morgan, 
Revista Eletrônica de Ciência Administrativa (RECADM) - ISSN 1677-7387

Faculdade Cenecista de Campo Largo - Coordenação do Curso de Administração

v. 2, n. 1, maio/2003 - http://revistas.facecla.com.br/index.php/recadm/

1996), ou seja, consegue perceber as alterações da situação em questão e responder de maneira satisfatória. Além destes aspectos, a metáfora do cérebro enfatiza a necessidade de um processamento de informação eficiente para um bom funcionamento organizacional.

A organização vista como cérebro, segundo Morgan (1996), possui características de autoaprendizagem, desenvolvendo a habilidade de aprender continuamente com as mudanças das situações de forma eficaz e criativa; de controlar os resultados através dos objetivos, metas e alvos, em vez de controlar os comportamentos por meio de regulamentos e regras; e de ser flexível ao produzir os resultados exigidos.

Morgan, ainda indica a possibilidade de analisar a organização como cultura. Assim, a organização nesta concepção é percebida como uma espécie de reflexo do padrão de desenvolvimento de "sistemas sociais de conhecimento, ideologia, valores, leis e rituais quotidianos." (MORGAN, 1996, p.117). As organizações vistas como cultura, segundo este autor, possuem rituais característicos que constituem sua própria cultura e que influenciam na maneira como os trabalhadores desenvolvem suas tarefas. Conhecer os processos de construção da realidade destas organizações permite entender os objetos, as ações, as metas, as atividades, as expressões e as articulações que estruturam as relações organizacionais.

Desta forma, a organizacão pode ser compreendida quando se conhece a maneira pela qual ocorreu a evolução cultural da sociedade na qual esta organização está inserida. Assim como, "compreendendo os fatores culturais que configuram os indivíduos e as suas organizações, têmse metas para compreender importantes diferenças transnacionais no comportamento organizacional." (MORGAN, 1996, p.124).

Merece salientar que as organizações adotam diferentes modelos de gestão, compreendidos como: " práticas administrativas colocadas em execução pela direção de uma empresa para atingir seus objetivos (CHANLAT, 1996, p.119). Assim, o autor ao analisar os modelos de gestão, indica como principais: taylorismo e neotaylorismo, tecnoburocrático, excelência e participativo. Pode-se observar que na atualidade, o modelo mais difundido é o da excelência que exige um comprometimento total e adesão passional dos trabalhadores, havendo conseqüências ao seu bem-estar e à sua saúde.

O tema modelos organizacionais e estratégias de gestão de recursos humanos, vem sendo estudado por alguns autores na realidade brasileira, entretanto existe uma grande lacuna, especialmente sobre seus reflexos nos trabalhadores. Assim, é de extrema importância um melhor conhecimento sobre as novas estratégias destes modelos, uma vez que sendo largamente utilizados nas diversas organizações, sendo necessário analisar as suas repercussões na esfera dos sujeitos-trabalhadores. 
Revista Eletrônica de Ciência Administrativa (RECADM) - ISSN 1677-7387

Faculdade Cenecista de Campo Largo - Coordenação do Curso de Administração

v. 2, n. 1, maio/2003 - http://revistas.facecla.com.br/index.php/recadm/

\section{OBJETIVOS}

Analisar os modelos adotadas em organizações contemporâneas e seus reflexos na gestão de recursos humanos.

Avaliar as percepções dos trabalhadores sobre as estratégias de gestão adotadas na organização e as repercussões no seu bem-estar.

\section{DESENVOLVIMENTO DO ESTUDO}

O presente estudo caracteriza-se como um levantamento de corte-transversal, de natureza descritiva. Possui um caráter exploratório e adota o modelo típico de estudo de caso. As estratégias metodológicas foram estruturadas em dois momentos e podem ser assim sintetizadas: a) realização de entrevistas com informantes-chave e análise de documentos da organização visando caracterizar o seu modelo e as estratégias de gestão de recursos humanos; b) aplicação de questionário com os trabalhadores, e complementação com entrevistas semidirigidas, para avaliar as suas percepções sobre as estratégias de gestão de recursos humanos.

Decidiu-se pela inclusão, apenas, da organização $X$ devido as peculiaridades identificadas no seu modelo organizacional, bem como por ser uma organização que adota uma estrutura diferenciada, pois tem o seu núcleo central localizado em Salvador-Ba e os serviços terceirizados são realizados no centro- sul do país. Assim, esta organização reúne um conjunto de aspectos que podem ser considerados como um caso ilustrativo de organização contemporânea.

\section{Procedimento para coleta e análise dos dados}

A coleta de dados foi realizada na própria organização e durante a jornada de trabalho.

Em um primeiro momento foi solicitado que um informante-chave (diretor/proprietário), falasse espontaneamente sobre a organização - sua estrutura e funcionamento visando melhor caracterizar o contexto e orientar a estruturação das próximas entrevistas. Em um segundo momento, as entrevistas com informante-chave foram semi-dirigidas buscando uma melhor apreensão da estrutura e a dinâmica da organização.

Adotou-se para obter informações dos trabalhadores, um questionário sobre o trabalho que foi elaborado e validado na nossa realidade por Fernandes (1997) e possibilita a caracterização dos participantes e do trabalho através de informações pessoais, profissionais, do contexto de 
Revista Eletrônica de Ciência Administrativa (RECADM) - ISSN 1677-7387

Faculdade Cenecista de Campo Largo - Coordenação do Curso de Administração

v. 2, n. 1, maio/2003 - http://revistas.facecla.com.br/index.php/recadm/

trabalho e do trabalho em si. Adicionalmente, buscou-se informações sobre o bem-estar dos trabalhadores e seu estilo de vida.

Finalmente a análise dos dados de natureza descritiva e incorporou quatro eixos centrais - 1) a concepção da organização e seu funcionamento; 2) o modelo organizacional; 3) as estratégias de gestão de recursos humanos; 4) a ótica dos trabalhadores sobre a organização e as estratégias de gestão dos recursos humanos.

\section{Contexto}

A organização $X$ é uma empresa baiana do segmento de serviços - produção e distribuição de livros e que atua no território nacional. Esta organização existe há 8 anos e neste período a sua produção foi de aproximadamente 60 livros. O editor é o próprio diretor-proprietário. O esquema organizacional, aparentemente adota a estrutura simples, (ROBBINS, 1999 p.306) pois suas características incorporam um baixo grau de departamentalização, esferas definidas de controle, autoridade centralizada em uma única pessoa e pouca formalização nas relações interpessoais.

A estratégia básica adotada pela organização $X$ é da flexibilidade, tendo no núcleo central uma estrutura que comporta poucos trabalhadores fixos, sendo que a operacionalização das suas atividades, especialmente a produção, depende de parcerias e terceirização dos serviços.

\section{Participantes}

Participaram do estudo os dirigentes $(n=3)$ e os trabalhadores do núcleo central ${ }^{2}(n=10)$ da Organização X.

Quanto ao perfil dos trabalhadores a maioria é de do sexo feminino $(77,8 \%)$ e tem nível de escolaridade superior - completo/incompleto (55,5\%).

Interessante observar que as atividades realizadas pelos trabalhadores da empresa são distribuídas, entre vendas e marketing (33,3\%), e indistintamente por todas as demais atividades inerentes ao seu negócio - coordenação, administração, vendas, marketing, administração financeira, administração da produção, serviços gerais e serviços externos.

O tempo médio de empresa destes trabalhadores é de 4 anos, havendo alguns com mais de 8 anos e existe, apenas, um trabalhador com menos de 6 meses. Esta informação denota baixa rotatividade de trabalhadores nesta empresa.

A média de idade dos participantes é de 32,7 anos.

\section{EIXO-1 A concepção da organização e seu funcionamento}


Revista Eletrônica de Ciência Administrativa (RECADM) - ISSN 1677-7387

Faculdade Cenecista de Campo Largo - Coordenação do Curso de Administração

v. 2, n. 1, maio/2003 - http://revistas.facecla.com.br/index.php/recadm/

O pressuposto básico da organização $X$ para o seu desenvolvimento empresarial consiste em considerar que "....cada indivíduo é uma empresa...". Além do objetivo de toda empresa privada de obtenção de lucro, adota como objetivo subsidiário a comercialização de livros que visem o desenvolvimento pessoal e empresarial. Neste sentido, segundo $Z^{3}$ " “... o nosso negócio é a produção de livros que ajudem as pessoas, e as empresas a serem mais produtivas, mais lucrativas dentro de um contexto humanista".

Considerando a natureza do negócio - produção de livros, parece existir um certa confusão sobre a concepção de editora e de editor. Segundo Z "... uma editora pode existir sem ter uma empresa (...). Na realidade, a editora é aquela que tem a capacidade ou traduz uma idéia e a coloca em formato de livro e circula no mercado, de múltiplas maneiras. Assim, esse processo pode ser todo terceirizado. Por exemplo, uma gráfica não é editora, gráfica é indústria gráfica, encarrega-se da reprodução é um outro segmento do negócio (...) No Brasil existem algumas empresas que incorporam tudo, que também têm gráfica. Mas pode-se ter uma editora que tenha todo o seu processo de produção terceirizado".

A relação da empresa com os profissionais que possuem vínculo empregatício e com as empresas terceirizadas é pautada nos pressupostos de confiança e fidelidade, visando garantir a qualidade do produto.

Um aspecto interessante observado nesta organização indica que suas concepções e funcionamento são fortemente influenciados pelas características de empresa de estrutura simples, especialmente com baixo grau de departamentalização e ênfase nas relações interpessoais. Segundo Robbins (1999, p.306-307), entre outros aspectos característicos, a organização com estrutura simples, é enxuta, geralmente tem dois ou três níveis hierárquicos, poucos trabalhadores e centralização na tomada de decisões. Estas características podem ser observadas em pequenos negócios onde o proprietário e o gerente são a mesma pessoa e têm a vantagem de funcionar de forma simples, além de apresentar rapidez e flexibilidade.

Ė possível identificar na organização $X$, uma aparente contradição nas suas concepções e princípios, transitando da centralização à descentralização do processo decisório, bem como uma certa ambigüidade de papéis, especialmente, o do diretor/proprietário. Todavia, estas aparentes ambigüidades e contradições parecem não ser foco de conflitos no ambiente organizacional, possivelmente em função da natureza da liderança exercida pelo diretorproprietário e do envolvimento da equipe de trabalhadores com o negócio da organização.

\footnotetext{
${ }^{2}$ Trabalhadores com vínculo empregatício com a Organização X

${ }^{3}$ Informante-chave
} 
Revista Eletrônica de Ciência Administrativa (RECADM) - ISSN 1677-7387

Faculdade Cenecista de Campo Largo - Coordenação do Curso de Administração

v. 2, n. 1, maio/2003 - http://revistas.facecla.com.br/index.php/recadm/

Pode-se observar ainda que a Organização $X$ adota princípios que se aproximam de concepções contemporâneas sobre organização, uma vez que o núcleo de trabalhadores centrais exerce o papel de editor e, também, realizam a formatação da primeira versão do produto final - o livro. Por outro lado, a organização terceiriza todas as atividades relacionadas à produção. Estes aspectos, ilustram o modelo de organização típica que surge com advento da reorganização produtiva - núcleo central, flexibilidade e terceirização dos serviços. Aliada a estas características, a organização $X$ encontra-se muito vinculada ao ambiente externo, adotando freqüentes ajustes frente as mudanças do perfil de consumidor, concorrência e incertezas do mercado.

A reestruturação do setor produtivo no cenário brasileiro é analisada por Nogueira et alii (1999, p.30-31), que indica os principais impactos a partir da década de 70. Além deste aspecto, o autor salienta que a partir da década de 90, a tendência tem sido da adoção de "estratégias de produtividade e qualidade frente a concorrência internacional" através do Programa Brasileiro de Qualidade e Produtividade. Todavia, a organização X, apesar de apresentar outras características inerentes a reorganização produtiva, como as práticas de externas das atividades - terceirização - não explicita claramente a adoção de estratégias vinculadas a produtividade e qualidade, inerentes ao Programa Brasileiro.

\section{EIXO-2 O modelo organizacional}

As principais características da Organização $X$ se aproximam, simultaneamente, de uma organização de estrutra simples e de equipe, pois realizam as atividades do planejamento e algumas das de produção, terceirizam a parte gráfica da produção e realizam o marketing e as próprias vendas. Segundo Z “.... nós temos aqui um representante de cada área ou setor de uma empresa: a) uma pessoa de produção - a produção: pega o original e formam; b) uma pessoa na administração financeira; c) cinco pessoas na área de vendas e marketing $e$ finalmente temos uma pessoa que também conduz todo o processo".

Quanto ao Conselho editorial esta atividade é exercida por uma única pessoa o diretor/proprietário. Neste sentido Z, salienta que “....na prática nós nunca tivemos, pois trabalhamos com oportunidades. Assim, um produto chega a nossas mãos ou a gente dá uma idéia, ou entende que aquilo é bom, sob o ponto de vista de conteúdo, ele tem uma possibilidade comercial, a gente vai lá e decide na base do risco. Alguns dão mais certo outros menos, mas graças a Deus a nossa história mostra que a resultante é extremamente positiva". Vale salientar que em casos excepcionais, quando o volume de trabalho é muito grande, a edição pode ser terceirizada. 
Revista Eletrônica de Ciência Administrativa (RECADM) - ISSN 1677-7387

Faculdade Cenecista de Campo Largo - Coordenação do Curso de Administração

v. 2, n. 1, maio/2003 - http://revistas.facecla.com.br/index.php/recadm/

Diferente do modelo adotado pela maioria das organizações que lidam com produção de bens e serviços, em relação à venda e à distribuição dos produtos, pois a organização X - núcleo central da empresa - realiza diretamente a venda e comercialização dos seus produtos. Neste sentido, $Z$ indica que “....a venda e a distribuição no Brasil são complicadíssimas, então somos os distribuidores dos nossos próprios livros e lutamos bravamente. Hoje nós distribuímos nossos próprios produtos, todos as grandes redes compram diretamente da gente, com também temos distribuidores outros, mas não exclusivos. O mercado brasileiro mata o distribuidor porque eles têm uma margem de $10 \%$ de lucro, e como o mercado é monopolista, melhor dizendo, oligopolista (...) existe meia dúzia de grandes redes que vendem $80 \%$ dos livros. Hoje todas as redes são clientes nossos, então por isso, nós também viramos distribuidores de nossos próprios livros se não fosse isso, não haveríamos sobrevivido. Por que não dá para depender de outros, também, esta atividade não é terceirizado, nós também somos distribuidores".

Como decorrência da reorganização produtiva e do avanço da microeletrônica, alguns segmentos de empresas do mercado se organizam sob a forma de empresas virtuais. Assim, tendem a descentralizar a produção, usando até o processo de terceirização. Por outro lado, estas empresas acabam por estabelecer um alto grau de centralização no processo decisório e acompanhamento da produção.. No caso da organização $X$, existem todas as etapas do processo produtivo (vertical) e a terceirização das atividades gráficas que são realizadas em São Paulo. Entretanto deve-se salientar conforme $Z$ “.... talvez a nível de mercado, temos a centralização de todas as etapas de produção seqüenciadas e verticalizadas, mas internamente busca-se a horizontalidade. É um caso específico da nossa realidade. Dando um corte observase as etapas de uma editora tradicional - o original manuscrito até o livro pronto".

Quanto ao controle de qualidade e as relações com a terceirização de serviços o aspecto crítico parece ser a atividade gráfica, uma vez que a organização $X$ tem menor controle. Neste sentido dois aspectos merecem ser analisados - qualidade da produção e o cumprimento de prazos.

Sobre a qualidade da produção, $Z$ indica que “... a gráfica tem maior interferência no processo de qualidade, pois o chargista você olha e a indicação ou contra-indicação é imediatamente gostei não gostei!. Mas, com a gráfica é diferente (...) Nós temos 8 anos de parceria com uma única gráfica em São Paulo. É um verdadeiro parceiro nosso! Inclusive, até os originais são entregues. Tamanha é a confiança! Nós entregamos tudo a ele, de vez em quando, olhamos no mercado o preço e brigamos com ele pra baixar. Na realidade, hoje funciona como estoque para gente, ele manda livros nossos para outros clientes. É um ganho bilateral, existe fidelidade, temos confiança quanto ao cumprimento de prazo e qualidade (...) È interessante 
Revista Eletrônica de Ciência Administrativa (RECADM) - ISSN 1677-7387

Faculdade Cenecista de Campo Largo - Coordenação do Curso de Administração

v. 2, n. 1, maio/2003 - http://revistas.facecla.com.br/index.php/recadm/

esta parceria ser realizada por empresa de São Paulo, pois caso exista problema com o fornecedor rapidamente busca-se uma solução. Na Bahia, existe a qualidade gráfica, de impressão, mas não tem a qualidade de confecção de livros Hoje a coisa está de tal forma que exige uma especificidade, existe máquinas só para produção de livros".

Deve-se observar que o processo de terceirização entre a organização $X$ e a empresa gráfica, diferente de outras experiências do mercado, é uma parceria sólida que na atualidade inspira fidelidade e confiança. Um aspecto interessante é a opção por uma gráfica do centro-sul, que poderá estar alicerçada, além dos aspectos tecnológicos envolvidos, em outros elementos vinculados à cultura organizacional voltada para a qualidade do produto e competitividade empresarial.

Quanto ao cumprimento de prazos, este não parece ser um aspecto central no processo produtivo da Organização $X$ pois com as características das terceirizações escolhidas este problema não é identificado. De acordo com Z, “... nunca ocorreu em 8 anos de chegar um livro aqui fora da data. Houve momento de estresse de chegar em 24 horas antes, às vezes por culpa até nossa que mandamos atrasados. Mas nunca tivemos esse problema. Ocorreu problemas técnicos sim, mas resolvidos...".

\section{EIXO-3 As estratégias de gestão de recursos humanos.}

Envolvimento, polivalência, iniciativa e comprometimento são os pilares das estratégias de gestão de recursos humanos adotados na organização $X$.

Segundo Z: “ ..... buscamos incentivar as pessoas a tomarem decisões (...) faça o que achar melhor, mas na medida do possível se você tiver tempo e condições de perguntar a alguém que tem mais experiência divida, caso contrário faça..." Neste sentido, é interessante observar que independente do nível hierárquico existe um completo envolvimento dos trabalhadores com o negócio da organização.

Quanto aos papéis e responsabilidades dos trabalhadores - não existe um script, definido é um processo onde os trabalhadores participam do conjunto de atividades. Existe a responsabilidade prioritária de uma pessoa - área administrativa, financeira - mas existe a participação dos demais trabalhadores.

Todos os trabalhadores centrais têm vínculo empregatício com a Organização. Quanto aos trabalhadores terceirizados, exercem suas atividades fora da empresa e são contratados por produto. Existem algumas terceirização de serviços que são típicas nesta organização: a) correção de texto e capista (capa artistíca) - paga-se pelo produto, pelo trabalho realizado; b) assessoria de imprensa - paga por período, contrato de 6 meses; c) o chargista e o ilustrador, a 
Revista Eletrônica de Ciência Administrativa (RECADM) - ISSN 1677-7387

Faculdade Cenecista de Campo Largo - Coordenação do Curso de Administração

v. 2, n. 1, maio/2003 - http://revistas.facecla.com.br/index.php/recadm/

cada produto identifica-se o profissional mais adequado no mercado e contrata-se para a atividade específica, um profissional freelance.

Sobre as estratégias de gestão de pessoas e os pressupostos para a seleção de pessoal, segundo Z, “.... uma das característica que eu peço na seleção é humildade, iniciativa, e particularmente, a humildade..." Quanto a política de remuneração, de acordo com informações da organização, é um aspecto problemático e um grande desafio. Observa-se que esta organização não tem políticas formalizadas quanto a gestão de pessoas e remuneração Segundo Z “...é um problema sério (...) tenho um sonho de colocar todo mundo para ter um salário básico mínimo e remuneração variável. Acredito que no futuro essa relação de carteira assinada vai terminar e defendo esta tendência. A idéia é que no futuro terá um empreendedor aglutinando pessoas que podem agregar valor e todo mundo vai ganhar proporcional e vão estar juntos enquanto dura. Eu entendo que essa vai ser a organização do futuro ...."

Quanto ao desenvolvimento de pessoas, é interessante que não existe um programa formal para treinamento e desenvolvimento. Segundo $Z$ “....existem oportunidades e, eu diria, que o que funciona mesmo é o treinamento diário, é o desafio do cotidiano. As pessoas fazem sugestões, agregaram valor (....) todo mundo dá sua idéia, opina e participa ....". Neste sentido, é interessante salientar que as modernas organizações estão incorporando as práticas de desenvolvimento de pessoas como uma das estratégias para 0 desenvolvimento organizacional. Assim, Nogueira et alii (1999, p.33) assinalam que a necessidade de aumentar a produtividade e a qualidade, conduzem à otimização do uso do potencial humano como ativador do processo nas organizações.

\section{EIXO-4 A ótica dos trabalhadores}

Os trabalhadores avaliaram o significado do trabalho através da escala do MOW que consiste na avaliação comparativa do grau de importância que as esferas do lazer, comunidade, trabalho, religião e família exercem em suas vidas.

Considerando o número de participantes do estudo, decidiu-se não realizar a análise quantitativa destes elementos, optando-se pela descrição da avaliação. Assim, observou-se que a esfera familiar ocupa um papel central na vida destes trabalhadores, seguido da esfera do trabalho. Dentro desta perspectiva de análise, pode-se assinalar que o trabalho exerce uma importância fundamental na vida dos participantes deste estudo. 
Revista Eletrônica de Ciência Administrativa (RECADM) - ISSN 1677-7387

Faculdade Cenecista de Campo Largo - Coordenação do Curso de Administração

v. 2, n. 1, maio/2003 - http://revistas.facecla.com.br/index.php/recadm/

Quanto a variedade do trabalho, os participantes indicam a existência desta característica no cotidiano.

Sobre as condições de trabalho, os trabalhadores indicaram que dispõe do material e equipamentos necessários para realizarem suas atividades. Adicionalmente, consideram que as condições ambientais (temperatura, iluminação e ruído) são adequadas.

Outros aspectos do ambiente psicossocial da organização foram avaliados pelos trabalhadores, revelando que algumas vezes recebem informações - feedback - dos seus supervisores a respeito do seu desempenho no trabalho.

Os trabalhadores consideram o ritmo de trabalho intenso e percebem as cargas de trabalho como excessivas, embora com baixo nível de exigência física.

Por outro lado, os participantes não registram a exigência de solicitações para realização de tarefas conflitantes, apesar do trabalho freqüentemente ter alto nível de exigência mental. É interessante ressaltar que os trabalhadores revelam que participam da tomada de decisões administrativas sobre suas tarefas, sendo que o clima organizacional foi avaliado de forma positiva.

Quanto as informações referentes ao controle do trabalho, a maioria dos participantes revelam que sempre realizam o seu trabalho independente de outras pessoas, que têm oportunidades de fazerem o trabalho do inicio ao fim e podem auto-avaliar a qualidade da execução do seus trabalhos, podendo perceber se estão realizando bem ou mal a sua tarefa. De forma coerente, os trabalhadores indicaram que visualizam o seu trabalho em toda a sua amplitude e que têm conhecimento sobre os objetivos e razões das suas tarefas, além de conhecerem ou serem informados sobre as etapas posteriores do trabalho. Os trabalhadores da organização revelam que têm a oportunidade de completar o trabalho que iniciaram e, também, têm autonomia para realizarem o trabalho por conta própria e decidem o quê e como farão o seu trabalho.

A participação na tomada de decisões, na perspectiva técnica, é considerada pelos trabalhadores como existente e adequada à natureza do trabalho, bem como participam do planejamento do trabalho.

Os trabalhadores avaliam de forma diferente dos gestores, alguns aspectos da organização, em especial as estratégias de gestão de recursos humanos e a política de terceirização dos serviços. Neste sentido, as estratégias de avaliação de desempenho, promoção e remuneração - tenderam a uma avaliação mediana.

O aspecto que recebeu uma avaliação mais crítica dos trabalhadores diz respeito ao processo de terceirização dos serviços. A política de terceirização adotada em X, tendeu a uma avaliação 
Revista Eletrônica de Ciência Administrativa (RECADM) - ISSN 1677-7387

Faculdade Cenecista de Campo Largo - Coordenação do Curso de Administração

v. 2, n. 1, maio/2003 - http://revistas.facecla.com.br/index.php/recadm/

de média a negativa, enquanto a qualidade dos serviços terceirizados recebeu uma avaliação negativa dos trabalhadores da organização contratante.

O modelo da organização $X$ tem correspondência com as estratégias organizacionais contemporâneas decorrentes da denominada reorganização produtiva - núcleo central e descentralização de serviços - flexibilidade e forte terceirização. Entretanto, diferente da tendência atual, não é identificada na organização $X$ as estratégias vinculadas a produtividade e qualidade - concorrência.

Quanto as estratégias de gestão de pessoas, não são observadas as tendências atuais inerentes a implementação de estratégias para desenvolvimento de pessoas, em especial, no que diz respeito à remuneração estratégica.

O clima organizacional e o forte envolvimento dos trabalhadores parecem ser determinados pelo modelo de liderança exercido pelo diretoria.

Ė possível identificar na organização $X$, segundo as metáforas adotadas por Morgan, características que são próprias da metáfora das máquinas como centralização do processo decisório, associada a características da metáfora do cérebro, em particular, a capacidade de ser processadora de informações e de promover de aprendizagem a partir dos processos vivenciados pelos seus trabalhadores e as relações com o mercado.

Os aspectos relacionados ao modelo de gestão de acordo com Chanlat (1995), podem ser identificadas características típicas do modelo neotaylorista, possuindo algumas aproximações com a gestão em grupo e o modelo da excelência, preconizando a produtividade e a qualidade. Vale salientar, o aparente paradoxo, entre o modelo de produção seqüenciada adota pela organização X e a horizontalidade nas decisões

\section{CONCLUSÃO}

A organização $X$ incorpora um conjunto de características das organizações contemporâneas: núcleo central com poucos trabalhadores, flexibilização e forte processo de terceirização dos serviços.

As suas características essenciais traduzem uma estrutura de organização simples predomínio das relações interpessoais, controle gerencial central e baixa departamentalização. Também, observa-se a tentativa de adoção na organização, do trabalho em equipe.

Quanto ao modelo organizacional, de acordo com as metáforas de Morgan, esta organização assemelha-se à metáfora da máquina, em virtude da racionalidade do modelo adotado no processo produtivo. Muito embora não seja dominante, é possível identificar características da 
metáfora do cérebro visto pelo processo de aprendizagem interno e das relações estabelecidas com o mercado.

Quanto à terceirização dos serviços existe um certo paradoxo entre as percepções dos trabalhadores e da diretoria. Assim, os trabalhadores não visualizam os aspectos positivos mencionados pela diretoria sobre a qualidade dos serviços terceirizados e assumem uma visão mais crítica sobre esta qualidade.

Merece destaque que apesar de cada vez mais complexificada a gestão de recursos humanos na atualidade, esta organização adota um modelo empresarial que incorpora as novas estratégias - descentralização dos serviços e forte terceirização - entretanto ainda não adota as estratégias de gestão de recursos humanso necessárias ao siatema de qualidade e competitividade empresarial.

\section{REFERÊNCIAS BIBLIOGRÁFICAS}

ARAÚJO, Maria Arlete D. de; MOREIRA, Carlos Antônio de L. Gerenciamento das pessoas em uma Associação de Trabalho: novas formas de participação?. Revista O \& S- Organizações \& Sociedade, Salvador, v.8, n.22, p. 75-90, set./dez. 2001

CARVALHO, R. Q. Capacitação Tecnológica Limitada e Uso do Trabalho na Indústria Brasileira. São Paulo em Perspectiva, 8 (1): 133-143, jan/mar 1994.

CHANLAT, JEAN-FRANÇOIS Modos de gestão, saúde e segurança no trabalho. In: DAVEL, E \& VASCONCELOS (org) Recursos Humanos e subjetividade. Petropólis: Vozes, 1995.

DELLAGNELO, Eloise L.; SILVA, Clóvis L. M. da. Novas formas organizacionais: onde se encontram as evidências empíricas de ruptura com o modelo burocrático de organizações?

Revista O \& S - Organizações \& Sociedade, Salvador, v. 7, n.19, p.19-33, set./dez. 2000

DRUCK, M. G. Globalização e Reestruturação Produtiva: o Fordismo e/ou Japonismo. Revista de Economia Política. v. 19, n. 2 (74), abr/jun 1999.

FERNANDES, S.R.P. Tecnologia Informática e Saúde Psíquica - fatores psicossociais. (Tese de Doutorado). ISC/UFBa, 1997.

MENDES, A. M. B. Os Novos Paradigmas de Organização do Trabalho: Implicações na Saúde Mental dos Trabalhadores. Revista Brasileira de Saúde Ocupacional. n. 85/86, v.23, set 1997.

MORGAN, Gareth. Imagens da Organização. São Paulo: Atlas, 1996.

MOURA, M. A Novas Tecnologias. Revista Brasileira de Saúde Ocupacional. n.79, v.21, $\mathrm{jul} / \mathrm{set}, 1993$, p. 63-75. 
Revista Eletrônica de Ciência Administrativa (RECADM) - ISSN 1677-7387

Faculdade Cenecista de Campo Largo - Coordenação do Curso de Administração

v. 2, n. 1, maio/2003 - http://revistas.facecla.com.br/index.php/recadm/

NOGUEIRA, A.M; BARRETO, A.P; MACIEL, C; ROSINHA, R.O Globalização: reestruturação produtiva e impactos na gestão de recursos humanos. In: PIMENTA, S.M (org). Recursos humanos: a dimensão estratégica. Belo Horizonte:UFMG, 1999.

ROBBINS, Stephen. P. Comportamento Organizacional. São Paulo:Atlas, 1999.

SCHAFF, A. A Sociedade Informática. S.P.: Editora Unesp/Brasiliense, 1995.

VELOSO, H.M; ROCHA, C.H; LANARI, C.S \& ARRUDA, A.G . As transformações no mundo do trabalho. In: PIMENTA, S.M (org). Recursos humanos: a dimensão estratégica. Belo Horizonte:UFMG, 1999. 